\title{
Carnaval dos animais: Uma leitura zoológica do romance Os cus de Judas
}

Luiz Maria Veiga ${ }^{1}$

RESUMO: Examinar os temas da transformação política e social (guerra colonial, fim do fascismo, revolução e contra-revolução) representadas simbolicamente nos motivos zoológicos e nas metamorfoses entre homens e animais ou vice-versa. Diálogo entre o romance e a proposta de um "inconsciente político" feita por Fredric Jameson. Conexão, por essa via, com o texto de José Cardoso Pires "Mozart, o poeta e o cão-polícia" do livro A cavalo no diabo.

ABSTRACT: To investigate themes related to social and political transformations (the colonial war, the fall of fascism, revolution, and counterrevolution), symbolized by zoological motifs and by the metamorphoses from human to animal form and vice versa. Dialogue between the novel and the idea of "political unconscious" as proposed by Fredric Jameson. Connection, by this means, to the text "Mozart, o poeta e o cão-polícia", by José Cardoso Pires.

PALAVRAS-CHAVE: Motivos zoológicos; guerra colonial; inconsciente político; metamorfose.

KEYWORDS: Zoological motifs; colonial war; political unconscious; metamorphoses.

\section{Romance com fauna}

$\mathrm{Na}$ abertura do romance Os cus de Judas, de Antonio Lobo Antunes, o inominado narrador-protagonista faz uma longa evocação, de mais ou menos quatro páginas, do Jardim Zoológico de Lisboa. E se o leitor se dispuser a fazer um inventário das espécies presentes nessa lembrança, encontrará um Jardim Zoológico bastante povoado. Vejamos apenas os substantivos (ou sintagmas nominais) referentes a seus

1 Mestrando do Programa de Pós-Graduação da Área de Estudos Comparados de Literaturas de Língua Portuguesa, FFLCH-USP. Projeto: Retrato do colonizador e do colono: a representação da minoria branca em algumas obras da literatura angolana. E-mail: veigaluiz@uol.com.br. 
possiveis habitantes, encontrados no trecho: "girafa", "cães", "caniche", "pássaros", “avestruzes", "pingüins”, “catatuas", “hipopótamos", "cobras", "crocodilos", "lagartixas", "odor dos animais", "cães esqueléticos", "boi-cavalo", "papa-formigas", "pescada", "insetos", "rinocerontes", "unicórnio", "borboleta", "ursos brancos", "mandris", "leões", "traça”, "raposas", "águias", "mocho", "tigres", "camelos", "focas", "elefante", "tucanos", "hienas", “orangotangos", “aranhas", "gatos" [OCDJ, 7-10] $]^{2}$. Como o narrador não se refere apenas aos bichos efetivamente existentes no local, mas serve-se da linguagem para comentá-los e multiplicá-los com metáforas em que entram outros animais, a população zoológica do romance se amplia, incluindo, sem maior estranheza, como nos bestiários medievais, até mesmo seres puramente imaginários.

Há ainda outro fenômeno significativo que podemos destacar nesta primeira manifestação do tempo da memória encontrada no livro. Embora o narrador afirme que naquele então da infância "os bichos eram mais bichos", essa firmeza de identidade se esvanece logo em seguida com o surgimento de uma espécie de fórmula equalizadora em que cada animal lembrado sugere uma figura humana que the corresponderia. Vejamos: "a solidão de espaguete da girafa assemelhava-se à de um Gulliver triste"; "avestruzes idênticas a professoras de ginástica solteiras"; "pingüins trôpegos de joanetes de contínuo"; "catatuas de cabeça à banda como apreciadores de quadros"; "no tanque dos hipopótamos inchava a lenta tranqüilidade dos gordos" $(O C D J, 7)$. Teríamos então: girafa/Gulliver, avestruzes/professoras, pingüins/contínuos, catatuas/apreciadores de quadros, hipopótamos/[homens] gordos. Como para confirmar que essas intercambiantes zoo/antropomorfizações não são casuais, o narrador, logo em seguida, sugere à sua silenciosa interlocutora que também eles, ainda que imaginariamente, submetam-se ao mesmo processo: "Se fôssemos, por exemplo, papa-formigas, a senhora e eu (...)" (OCDJ, 8).

2 Antunes, 1985. As citações do romance serão identificadas pelas iniciais OCDJ seguidas do número da página. 
Algumas páginas adiante as possibilidades zoomórficas do casal são de novo lembradas: "Quem sabe se acabaremos a noite a fazer amor um com o outro, furibundos como rinocerontes com dores de dentes (...)" $(O C D J, 22)$. E em nova incursão rememorativa ao Zôo, o narradorprotagonista imagina a sua completa transformação:

Se eu fosse girafa amá-la-ia em silêncio, fitando-a de cima da rede numa melancolia de guindaste, amá-la-ia com o amor desajeitado dos exageradamente altos, mastigando o chiclete de uma folha pensativa, ciumento dos ursos, dos papa-formigas, dos ornitorrincos, das catatuas e dos crocodilos, e desceria trabalhosamente o pescoço pelas roldanas dos tendões para esconder a cabeça no seu peito em trêmulas marradas de ternura. $(O C D J, 27)$

É nossa intenção, no breve ensaio que se segue, aproveitar as sugestões contidas nestes primeiros apontamentos e mostrar como, ao longo do romance, as alusões e referências a animais (de todas as espécies e em variados modos) seguem sensivelmente presentes, e oferecer uma leitura e um sentido para o expressivo bestiário mais ou menos subterrâneo que percorre o texto.

\section{No fluxo do inconsciente politico}

Procuraremos empreender esta nossa leitura dialogando com sugestões feitas pelo professor Fredric Jameson em seu livro $O$ inconsciente político. Parece-nos que a trajetória do narradorprotagonista, submetido às circunstâncias históricas do colonialismo salazarista, que não chamaríamos tardio, mas atrasado, um subquadro específico daquilo que Jameson chama "capitalismo tardio", ou seja, o capitalismo da nossa época, da segunda metade do século XX para cá, parece-nos, como dizíamos, que essa trajetória pode ser comparada, em sua substância concretamente humana recriada pela literatura, com o caminho rumo à reificação ${ }^{3}$ exacerbada, destino a que esse modo de

3 "O conceito de reificação que foi desenvolvido nestas páginas explica a situação histórica em que a emergência do ego ou do sujeito centrado pode ser entendida: a 
produção tem conduzido a sociedade. Convém lembrar aqui que um personagem não é um indivíduo, mas uma criação, um simulacro, uma construção moldada pela sensibilidade do artista que pode reunir, em sua figura, uma pequena síntese daquilo que, também nas palavras de Jameson, seria socialmente simbólico, portanto algo em que os que tomam contato com o texto, na condição de membros dessa mesma sociedade, talvez venham a encontrar-se ali representados.

Mas antes de continuar a perseguição de um significado para a fauna que povoa o romance, pretendemos destacar alguns aspectos da maneira como ele foi estruturado.

\section{Tempos: presente, memória}

Embora o romance se inicie com uma rememoração (o Jardim Zoológico nos passeios da infância), devemos considerar que esse tempo já repousa, naquele momento inicial, sobre o presente da narrativa. "Não sei se lhe parece idiota o que vou dizer" $(O C D J, 7)$, é a fala do narrador-protagonista, no presente, dirigindo-se à sua interlocutora (e também, é claro, ao leitor, perfeitamente autorizado a imaginar-se no lugar dela), que introduz a lembrança dos domingos antigos. São esses dois eixos, superpostos, os formadores do arcabouço de sustentação de Os cus de Judas. O tempo do presente (mais curto, a travessia de uma noite até o amanhecer) serve de moldura, talvez fosse melhor dizer de pedestal, para o outro tempo, em que se inscreve o conteúdo da narrativa (bem mais longo, os vinte e sete meses de serviço militar em Angola, pelo menos, aos quais se reúnem lembranças da infância e também as posteriores ao regresso definitivo a Portugal).

No presente da narrativa há o encontro entre o narradorprotagonista e sua interlocutora muda, que jamais se manifesta

dissolução dos grupos sociais mais antigos, orgânicos ou hierárquicos, a mercantilização universal da força de trabalho dos indivíduos e seu confronto como unidades equivalentes dentro do quadro do mercado, a anomie desses novos sujeitos individuais 'livres' e isolados, com relação à qual só o desenvolvimento protetor de uma couraça monádica surge como uma espécie de compensação.” Jameson, 1982, p. 156. 
explicitamente, podemos dizer: de quem nós, os leitores, nunca ouvimos a voz. O encontro acontece num bar, percorre ruas de Lisboa, prossegue no apartamento do narrador-protagonista, tem um momento de fratura em que o veterano da guerra se isola no banheiro do apartamento para, numa mudança de interlocutora, dirigir seu discurso a Sofia, de quem adiante falaremos, e se encerra com a partida da companheira de travessia noturna e o conseqüente estado de solidão (crônica, reificada) a que ele retorna. Esse encontro não está datado com exatidão, mas sabemos o ano em que acontece pela autodescrição que o narradorprotagonista sugere, em determinado ponto da noite: "tome-me pelo jovem tecnocrata ideal português 79" (OCDJ, 64).

Entre esse primeiro tempo e o tempo da lembrança (pelo menos a sua parte mais substancial), há um intervalo de oito anos. Convocado para servir, como oficial médico, o Exército Português em operações de guerra na então ainda colônia de Angola, nosso protagonista para lá vai em fins de 1970 ou em janeiro de 1971 e lá permanece durante "vinte e sete meses (...) nos cus de Judas, vinte e sete meses de angústia e de morte juntos nos cus de Judas, nas areias do Leste, nas picadas dos Quiocos e nos girassóis do Cassanje" (OCDJ, 172), ou seja, até fevereiro ou março de 1973. Há várias marcações temporais no texto remetendo a esse intervalo: "os eucaliptos de Ninda (...) nesse tempo, abril de 71" $(O C D J, 52)$; uma data precisa para um acontecimento singular: "na tarde de 22 de junho de 71, no Chiúme, em que me chamaram ao rádio para me anunciar (...) o nascimento da minha filha" (OCDJ, 58); a licença única em Lisboa, autorizado "a regressar da guerra da África para conhecer a filha, numa dessas madrugadas de novembro" (OCDJ, 70 ), e como a filha é uma criança "de quatro meses" (OCDJ, 75), sabemos que é novembro de 1971; no mês seguinte ele está "no Chiúme, entende, no Natal de 71, primeiro Natal de guerra após quase um ano na mata" (OCDJ, 96).

Parece-nos importante destacar dois pontos acerca da estruturação do tempo (e da narrativa) no romance. No primeiro, gostaríamos de lembrar que aquilo a que chamamos bestiário mais ou 
menos subterrâneo que percorre o livro, e a que voltaremos, está presente nos dois tempos encontrados na narrativa de forma mais ou menos semelhante e equilibrada, constituindo, portanto, um elemento unificador da obra. Os múltiplos e onipresentes cães, por exemplo, tanto se manifestam nas madrugadas de Lisboa ("o ladrar dos cães nas quintas longe mudou ligeiramente de tonalidade") (OCDJ, 151) como nos acampamentos militares nas vastidões do sertão angolano ("os cães do quartel a farejarem-me a roupa, gulosos do sangue dos meus camaradas feridos") (OCDJ, 132).

O segundo ponto diz respeito às marcas cronológicas que fizemos questão de assinalar. Parece-nos que, com elas, o autor situa conscientemente seu romance num determinado tempo e lugar histórico, talvez para nos dizer que sua ficção não se refere a nenhum mergulho intimo e confessional, embora isso também ocorra, mas remete a um tempo e a uma sociedade claramente definidos, que ele não se propõe simplesmente a mimetizar, imprimindo, com isso, ao leitor e ao realismo de sua escrita, talvez uma sensação de maior realidade, mas acreditamos que ele também queira propor um confronto e uma discussão sobre esse quadro, essa sociedade e sobre as humanas possibilidades dentro dela.

Procurando clarificar melhor o que pretendemos dizer quando falamos nessa possível proposta de discussão, vamos examinar em seguida como aparece um outro tempo, também muito marcadamente presente no texto do romance de Lobo Antunes: o tempo da História, esse processo que marca o limite da experiência humana ${ }^{4}$ a fornecedora da matéria-prima que constitui o inconsciente politico, essa imensa "narrativa ininterrupta" 5 para a qual afluem todas as outras narrativas.

\footnotetext{
4 Jameson fala "da onipresença da História e da implacável influência do social”, 1982, p. 18 .

5 Jameson, 1982, p. 18.
} 


\section{De Salazar aos cravos murchos: romance politico}

Fredric Jameson abre o primeiro capítulo de seu livro dizendo que nele "vai argumentar em favor da prioridade da interpretação política dos textos literários" e que esta perspectiva deva ser "horizonte absoluto de toda leitura e de toda interpretação"6. No caso do romance de Lobo Antunes, nem será necessária toda essa ênfase argumentativa, pois o autor parece estar em bastante acordo com a postura de Jameson. Também ele faz questão de explicitar as ações políticas (as ações do poder, as ações movidas pela dominação e pelo conflito entre as classes) como pano de fundo e como determinante para o destino de seu personagem. O narrador-protagonista não escolhe ir para a guerra de Angola, é para lá mandado. E os que para lá o mandam aparecem emblematicamente logo no primeiro capítulo do romance, na descrição da casa das tias do narrador:

O espectro de Salazar pairava sobre as calvas pias labaredazinhas de Espírito Santo corporativo, salvando-nos da idéia tenebrosa e deletéria do socialismo. A PIDE prosseguia corajosamente a sua valorosa cruzada contra a noção sinistra da democracia, primeiro passo para o desaparecimento, nos bolsos ávidos dos pequenos jornaleiros e auxiliares de escritório, do faqueiro de cristofle. O cardeal Cerejeira, emoldurado, garantia, de um canto, a perpetuidade da Conferência de São Vicente de Paula, e, por inerência, dos pobres domesticados. (OCDJ, 12-13)

Temos então, num lado, os de cima: "Salazar", "PIDE”, “cardeal Cerejeira", três pilares do regime ditatorial, o famigerado Estado Novo; e no outro, o povo-ré, a arraia-miúda, os de baixo: "pequenos jornaleiros”, “auxiliares de escritório”, os “pobres”, por enquanto, “domesticados”. Mas há mais dessa gente na casa, porém escondida, pois mostra figuras inadequadas e trata-se de cena pouco apresentável na parede da sala, ao lado dos sustentáculos do poder: "O desenho que representava o povo em uivos de júbilo ateu em torno de uma guilhotina libertária fora definitivamente exilado para o sótão” (OCDJ, 13).

\footnotetext{
6 Jameson, 1982, p. 15.
} 
O equilíbrio desse quadro vai se desarranjar com a guerra da África. Há, no romance, vários momentos que marcam esse processo de ruína. A reflexão e a consciência política vão surgindo do contato com a realidade:

A cada ferido de emboscada ou de mina a mesma pergunta aflita me ocorria (...): são os guerrilheiros ou Lisboa que nos assassinam, Lisboa, os americanos, os russos, os chineses, o caralho da puta que os pariu combinados para nos foderem os cornos em nome de interesses que me escapam (...) (OCDJ, 35)].

O papel da jovem oficialidade, os que seriam depois os capitães de Abril, também é indício dos ventos da mudança que se prepara, bem como o atrito mais ou menos constante com a famigerada e brutal polícia política, a PIDE ou DGS, outro claro sinal da fração já instalada no interior do regime:

(...) se me perguntam por que continuo no Exército respondo que a revolução se faz por dentro, explicava o capitão de óculos moles e dedos membranosos atrás do seu cigarro eterno, o capitão que puxou da pistola para o pide magrinho que atirara um pontapé a uma rapariga grávida e o expulsou da companhia indiferente às ameaças azedas do outro, o capitão de malas cheias de livros e de revistas estrangeiras que me contavam do que eu não sabia (...) $(O C D J, 41)$.

Mas se existe fração no regime, ela ainda não abalou o poder que manda de fato, como fica sabendo "o tenente" que "levantara uma ocasião" um inspetor da pide "pelo pescoço, por haver insultado de covarde um oficial que não estava presente" pois "logo do Comando de Zona os brigadeiros autoritários, deram a entender que quem entrasse em conflito com os heróicos patriotas da dêgêésse correria alguns riscos militares desagradáveis (...)". Quem resume lapidarmente o desequilíbrio de forças daquela conjuntura é o velho soba da máquina de costura avariada quando diz: "Sôr pide manda mais que os tropa —" $(O C D J, 66)$. As únicas revanches possíveis ainda são a imaginária, como a linguagem desabrida na carta mental endereçada ao ditador, em meio 
a um atendimento emergencial a vítimas de uma emboscada ${ }^{7}$, e alguma ocasional e individual, como

(...) na noite em que o sujeito [da PIDE] rasgou a nádega no caco quebrado da retrete, entende, lhe cosi o pandeiro sem anestesia, no cubículo do posto de socorros, sob as vistas contentes do enfermeiro, vingando um pouco, em cada berro seu, os homens calados que cavavam a terra, de pânico a fundir-se em enormes placas de suor nas costas magras, e nos fixavam com órbitas duras e neutras como seixos, esvaziadas de luz, tal as dos defuntos sem roupa, estendidos nos frigoríficos do hospital. $(O C D J, 113)$

E o conflito com a PIDE não era o único em que se viam envolvidos os militares portadores, como o narrador-protagonista, de alguma consciência da falta de sentido daquela guerra. Além de se sentirem acovardados diante da máquina repressiva, eram hostilizados, ao que parece, por todos os grupos em conflito. A começar pelos negros que, na condição de guerrilheiros, eram seus adversários diretos. Mas também pelos outros negros, os civis, os ditos dominados, "que no escuro da senzala Santo Antônio (...) gritavam - Vai na tua terra, português" (OCDJ, 126), tendo do outro lado "a hostilidade dos brancos de Angola, dos fazendeiros e dos industriais de Angola, reclusos nas suas vivendas gigantescas e repletas de antiguidades falsas” e que diziam aos militares: "- Se vocês cá não estivessem limpávamos isto de pretos num instante." (OCDJ, 98) Ou então: “- Não precisamos de vocês para nada." (OCDJ, 126)

O veterano da guerra colonial indica, à sua interlocutora, além dos evidentes sinais, sua opinião sobre os motivos da fratura instalada dentro do regime ter continuado a progredir: "Os fascistas fizeram grandes erros em África, percebe, grandes e estúpidos erros em África, porque o fascismo felizmente é estúpido, suficientemente estúpido e cruel para se devorar a si mesmo (...)” (OCDJ, 140).

Até que acontece o 25 de Abril de 1974, quando

\footnotetext{
7 Prezado doutor Salazar se você estivesse vivo e aqui enfiava-lhe uma granada sem cavilha pela peida acima uma granada defensiva sem cavilha pela peida acima (...) (OCDJ, 92).
} 
os senhores da guerra de Lisboa, os que no quartel do Carmo se cagavam e choravam vergonhosamente, tontos de pânico, no dia da sua miserável derrota, perante o mar em triunfo do povo, que arrastava, no seu impetuoso canto, como o Tejo, as árvores magras do Largo. (OCDJ, 144)

E em seguida, com direito ao cantante cubano Silvio Rodriguez e sua Pequeña serenata diurna numa citação errada e tudo, o

primeiro de maio de 74 que os políticos inquinavam já da massa folhada sem recheio dos seus discursos veementes, mas onde crescia nas ruas uma irresistivel fermentação de esperança, os ministros de Caetano borravam-se de medo na Madeira, os pides borravam-se de medo em Caxias, uma festa de labaredas vermelhas alastrava triunfalmente em Lisboa, quiero que me perdones los muertos de mi felicidad (...) (OCDJ, 55).

Mas os cravos da Revolução acabaram fenecendo (“Já murcharam tua festa, pá” diz Chico Buarque, na canção Tanto mar9, que poderia servir de trilha sonora para este trecho):

Se a revolução acabou, percebe?, e em certo sentido acabou de fato, é porque os mortos de África, de boca cheia de terra, não podem protestar, e hora a hora a direita os vai matando de novo, e nós, os sobreviventes, continuamos tão duvidosos de estar vivos que temos receio de, através da impossibilidade de um movimento qualquer, nos apercebermos de que não existe carne nos nossos gestos nem som nas palavras que dizemos, nos apercebermos que estamos mortos como eles (...) (OCDJ, 52-53).

\footnotetext{
8 O trecho correto da letra, segundo encarte do LP Chico Buarque citado adiante, é assim: "Y quiero que me perdonen / Por este dia / Los muertos de mi felicidad".

9 Chico Buarque - "TANTO MAR - 2a . edição, revista: Foi bonita a festa, pá / Fiquei contente / E inda guardo, renitente / Um velho cravo para mim / Já murcharam tua festa, pá / Mas certamente / Esqueceram uma semente / Nalgum canto do jardim / Sei que há léguas a nos separar / Tanto mar, tanto mar / Sei também quanto é preciso, pá / Navegar, navegar / Canta a primavera, pá / Cá estou carente / Manda novamente / Algum cheirinho de alecrim" - Encarte do LP Chico Buarque, Philips, 1978. Neste disco também há, como já vimos, uma gravação da Pequeña serenata diurna, de Silvio Rodriguez. Será apenas coincidência ou seria um fluxo comum do inconsciente político daquele momento, que reuniu Rodriguez, Chico Buarque e Lobo Antunes? Lembremos que o romance é de 1979, não sendo improvável, portanto, que o autor português conhecesse o disco.
} 
O resultado desse processo parece sugerir, pelo menos como uma das conseqüências, com certeza a mais importante, a reificação, reificação capaz de proporcionar uma consciência viva de aniquilamento, a imobilizante idéia de já estar morto, embora estando vivo. É outro dos pontos de contato entre este romance e a obra de Jameson, que tem exatamente na reificação um de seus principais temas.

Vistos, ainda que de modo fugaz, o tempo da História e a representação do processo explicitamente político no romance, podemos voltar ao nosso tema das mutações dos homens e dos animais.

\section{Metamorfoses, mudanças, transformações}

São as tias que, quando o sobrinho médico é convocado para a guerra, mais que lhe desejar, auguram-lhe a transformação e introduzem explicitamente o tema: "- Felizmente que a tropa há-de torná-lo um homem." (OCDJ, 12) Depois é a própria voz do narrador quem o reforça: ainda no quartel, antes da partida, "a família em júbilo vinha espiar a evolução da metamorfose da larva civil a caminho de guerreiro perfeito" (OCDJ, 15) e "quando embarquei para Angola, a bordo de um navio cheio de tropas, para me tornar finalmente homem, a tribo, agradecida ao Governo que me possibilitava, grátis, uma tal metamorfose, compareceu em peso no cais" (OCDJ, 13, todos itálicos nossos).

E são essas mesmas tias que contrariam, negam seus próprios prognósticos, quando o sobrinho aparece-lhes desmobilizado, "envergando um terno de antes da guerra que me boiava na cintura à laia de uma auréola caída” e uma delas sentencia: “- Estás mais magro. Sempre esperei que a tropa te tornasse um homem, mas contigo não há nada a fazer." (OCDJ, 173) Não teria havido, então, segundo elas, mudança nenhuma. As expectativas não se cumpriram. Ou seria apenas caso de incapacidade delas para perceber a transformação, distinguir o homem que ele não era (antes de ser soldado) do homem em que, afinal, ele se transformara (depois da experiência da guerra). 
Esses dois distintos senhores não podem ser considerados, de maneira nenhum, como sendo a mesma criatura.

Em dois momentos, pelo menos, o narrador-protagonista descreve a sua transformação e o que dela resultou:

De fato, e consoante as profecias da família, tornara-me um homem, uma espécie de avidez triste e cínica, feita de desesperança cúpida, de egoísmo, e da pressa de me esconder de mim próprio, tinha substituído para sempre o frágil prazer da alegria infantil, do riso sem reservas nem subentendidos, embalsamado de pureza, e que me parece escutar, sabe?, de tempos em tempos, à noite, ao voltar para casa, numa rua deserta, ecoando nas minhas costas numa cascata de troça. $(O C D J, 25)$

No segundo momento ele surpreende em si o mesmo riso bestial do inspetor da PIDE que lhe dá, cínica e brutalmente, a notícia da execução de Sofia $^{10}$, a amante negra que lhe deixou as únicas boas lembranças ${ }^{11}$ sobreviventes de toda aquela guerra. Viu-se:

(...) descerrando os dentes enormes numa satisfação de hiena. Porque foi nisto que me transformei, que me transformaram, Sofia: uma criatura envelhecida e cínica a rir de si própria e dos outros o riso invejoso, azedo, cruel dos defuntos, o riso sádico e mudo dos defuntos, o repulsivo riso gorduroso dos defuntos, e a apodrecer por dentro, à luz do uísque, como apodrecem os retratos nos álbuns, magoadamente, dissolvendo-se devagarinho numa confusão de bigodes. (OCDJ, 137)

E essa segunda descrição do homem transformado dá-nos também uma pista para outras metamorfoses, introduzidas no texto do romance logo em sua abertura, antes das tias do narrador explicitarem o tema. A associação que o narrador faz entre o seu riso e o de uma

\footnotetext{
10 - Era boa, hã? Estava feita com os turras. Comissária, entendes? Demos-lhe uma geral para mudar o óleo à rapaziada, e, a seguir, o bilhete para Luanda. (OCDJ, 136) 11 “(...) eu sentia a tua gargalhada vitoriosa imóvel na boca, riso de mulher liberta que nenhum pide, nenhum tropa, nenhum cipaio calaria, o teu riso que mesmo hoje, neste asséptico e odioso aquário de azulejos continuo a escutar (...)"(OCDJ, 133). Este retrato de mulher que é livre porque interiorizou a liberdade e recusa a submissão, que morre mas não se rende, talvez seja o melhor exemplo a destacar no romance, numa perspectiva voltada para a hermenêutica positiva que Jameson nos aconselha a também procurar nos textos que examinamos.
} 
hiena aponta para transformações que vão além das mudanças no homem, decorrentes do amadurecimento e da perda das ilusões. Estas seriam marcas da trajetória individual do personagem. Mas a trajetória coletiva do grupo em que o narrador-protagonista participa ultrapassa esses limites. A transformação do grupo vai além, parece alcançar o desumano ou mais que isso, praticamente descortina o rumo coletivo da animalização.

Para demonstrar essas afirmações com passagens do texto, precisamos primeiro observar a relativa ("espingarda entre os joelhos") normalidade do momento em que a tropa recém-chegada, ainda a caminho do seu destino, é recebida num de seus pontos de passagem:

(...) chegamos a Nova Lisboa, cidade ferroviária no planalto, de que guardo uma confusa lembrança de cafés provincianos e de vitrinas poeirentas, e do restaurante onde jantamos, de espingarda entre os joelhos, observados por mulatos de óculos escuros parados diante de cervejas imemoriais (...) (OCDJ, 29),

e contrastá-lo como o momento em que, de novo em trânsito, mas agora com uma longa temporada de "guerra [que] tornou-nos em bichos, percebe, bichos cruéis e estúpidos ensinados a matar", com essa experiência nas costas,

à chegada ao Luso veio um jipe avisar-nos que o general não consentia que dormíssemos na cidade, que expuséssemos na messe as nossas chagas evidentes. Nós não somos cães raivosos, berrava o tenente de cabeça perdida para o enviado do comando de Zona, diga a esse caralho do catano que nós não somos cães raivosos (OCDJ, 107).

Mas logo fica óbvio que o tenente, ainda que justamente indignado, ainda tem ilusões, e está errado quando afirma não serem eles cães raivosos. O narrador-protagonista corrige o tempo verbal da afirmativa do tenente, inventariando o processo que levou a essa transformação, à metamorfose coletiva sofrida pelo grupo:

Nós não éramos cães raivosos quando chegamos aqui disse eu ao tenente que rodopiava de indignação furiosa, não éramos cães 
raivosos antes das cartas censuradas, dos ataques, das emboscadas, das minas, da falta de comida, de tabaco, de refrigerantes, de fósforos, de água, de caixões, antes de uma berliet valer mais do que um homem e antes de um homem valer uma notícia de três linhas no jornal, Faleceu em combate na província de Angola, não éramos cães raivosos mas éramos nada para o Estado de sacristia que se cagava em nós e nos utilizava como ratos de laboratório (...) (OCDJ, 107-108, i. n. exceto para berliet).

Não éramos, mas agora somos, é o que nos parece dizer o narrador-protagonista. Isso, ou outra coisa, as alternativas existem, estão dadas: "cães raivosos", "nada”, "ratos de laboratório", mas não homens. Qualquer coisa, mas menos que homens. E essas, digamos, novas criaturas parecem logo se adaptar confortavelmente à sua nova condição: depois de

vinte e cinco meses de guerra nas tripas (...) nos divertíamos mordendo-nos como os animais se mordem nos seus jogos, nos ameaçávamos com as pistolas, nos insultávamos, furibundos, numa raiva invejosa de cães, nos espojávamos, latindo, nos charcos de chuva (...) (OCDJ, 150).

Muitas outras transformações zoomórficas podem ser encontradas no texto do romance, mas esse momento que mostra a consciência da passagem de soldados a cães raivosos parece-nos a mais expressiva de todas, a metamorfose exemplar que sintetiza todas as outras. Fredric Jameson, quando discute uma obra de Lévi-Strauss, as Mytologiques, fala numa "desconcertante fluidez desses feixes narrativos, em que as personagens humanas são incessantemente transformadas em animais ou objetos e novamente reassumem a forma humana"12. Se não podemos dizer que é isso que acontece com os personagens do romance de Lobo Antunes, podemos pelo menos afirmar que algo desse processo de constante transmutação está presente na linguagem com que esses personagens são construídos, no emaranhado de imagens que constituem a tessitura do texto. É este, em nossa opinião pelo menos, o sentido da presença de uma tão grande e

${ }^{12}$ Fredric Jameson, op. cit., p. 124. 
variada fauna, convivendo lado a lado com os personagens humanos, ao longo de toda a obra.

\section{Destino de pide, destino de cão}

Uma última coisa a assinalar a respeito dos agentes da polícia política: em alguns pontos determinados do livro podemos acompanhar a acentuada animalização imagética com tendência, digamos, ao repugnante, que estes passam a sofrer: "pelos rostos triangulares de lagartos furiosos dos pides" (OCDJ, 129), "um carcereiro armado, encostado à sombra da casa como uma hiena retesa antes do salto", "cabrão escorregou risos contentes" (OCDJ, 136). Essa tendência, que parece correr paralela ao processo de transformação de homens em cães raivosos pelo método que já verificamos, vai ser coroada num outro texto, de um outro livro, de um outro autor. Aqui, mais uma vez, podemos invocar o inconsciente político, esse subterrâneo da sociedade que nos permitiria trazer "para a superfície do texto a realidade reprimida e oculta dessa história fundamental"13 que é, essencialmente, como afirmou Marx, a história da luta de classes.

Um fluxo específico, alguma determinada corredeira do inconsciente político parece ter arrastado Antonio Lobo Antunes e José Cardoso Pires numa mesma e específica direção. O papel dos leitores é descobrir o fluxo e também se deixar arrastar por ele. Se o fizerem, poderão encontrar algo como o texto que se segue, com que nos deparamos num livro de crônicas do autor da Balada da praia dos cães. É uma história que ter-se-ia dado em 1980, diz respeito a certo português músico e escroque, alcunhado Mozart, e mais alguns personagens, que teria sido contada ao autor num bar de Londres por Gaspar, um outro português, conhecido eventual e igualmente escroque, mas em escala mais reduzida que a do músico:

13 Idem, p. 18. 
E vieram os pormenores. O Mozart a solfejar cheques sem cobertura, o Mozart em eclipses repentinos quando chegava o fim do mês ou quando apareciam certas visitas, o Mozart a viver num palacete arruinado, algures em Elephant and Castle, com uma criada e um galgo russo, o Mozart a chantagear um pide fugido ao 25 de Abril que lhe servia de escudeiro.

"Um pide?"

Gaspar soltou uma gargalhada:

"Um pide, um transmontano com cara de cão que só lhe serve para fazer punhetas ao galgo. Verdade. O maestro, que é todo aristocrata, tem a mania que o bicho há-de morrer virgem ou então não o quer misturado com cadelas doutra raça, nunca percebi. De maneira que põe o pide a funcionar. Primeiro com uma luvazinha de borracha tão transparente que era um gosto vê-lo a trabalhar naquele asseio, depois à mão nua porque o brutamontes do pide tem cá uns dedos de fada que só um polícia dos anjos seria capaz de ter. O sacana do cão tomou-lhe tal gosto que já não quer outra coisa."

"Qualquer dia, você vai ver, temos o galgo transformado em cão-polícia", disse eu. "Por enquanto ainda é só amante."

Gaspar sacudiu a cabeça a rir. "Um galgo amante dum pide." E a seguir: "O pide, percebe?, é que se transformou em cão. O pide, pois. Ele é que está sempre a mexer-lhe na picha mesmo depois do trabalhinho, ele é que o chama a toda hora a propósito disto ou daquilo, que é que julga? Anda-lhe no cheiro, como eu costumo dizer, e por acaso até já o vejo com cara de cão. Cara de cão, palavra. É ou não é de partir a moca e rir, um carnaval como este?"14

Depois deste tão bizarro caso de zoofilia agravado por zoomorfia, se tivéssemos de fazer algum comentário relacionando os dois textos, o de Lobo Antunes e o de Cardoso Pires, teríamos obrigatoriamente de nos lembrar de Marx, e do seu aforismo da História como tragédia e da sua repetição como farsa. Mas, diante de tão expressivo quadro, perfeitamente auto-explicativo, é melhor não fazer comentário nenhum e por aqui nos ficarmos.

\section{Referências bibliográficas}

ANTUNES, António Lobo. Os cus de Judas. Rio de Janeiro: Marco Zero, 1984. JAMESON, Fredric. O inconsciente politico: a narrativa como ato socialmente simbólico. Trad. Valter Lellis Siqueira. São Paulo: Ática, 1992.

PIRES, José Cardoso. A cavalo no Diabo. Lisboa: Dom Quixote, 1994.

14 "Mozart, o poeta, e o cão-polícia" in Pires, 1994, pp. 124-125. 


\section{Referências discográficas}

BUARQUE, Chico. LP Chico Buarque Stereo 6349398 Série de Luxo. Letras no encarte: "Pequeña serenata diurna" (Silvio Rodriguez), lado 2, faixa 4. "Tanto mar" (Chico Buarque), lado 2, faixa 5. Brasil: Polygram Philips, 1978. 